\title{
Therapeutic Potential of Thymoquinone and Its Nanoformulations in Pulmonary Injury: A Comprehensive Review
}

\author{
Naif A Al-Gabri, ${ }^{1,2}$ \\ Sultan AM Saghir, ${ }^{3}$ Sallah A Al- \\ Hashedi, ${ }^{4}$ Ali $\mathrm{H}$ El-Far, (iD ${ }^{5}$ \\ Asmaa $F$ Khafaga, (1D ${ }^{6}$ \\ Ayman A Swelum, $\mathbb{1}^{7}$ \\ Abdullah S Al-wajeeh, \\ Shaker A Mousa, $\mathbb{D}^{9}$ \\ Mohamed E Abd El-Hack, (D) ${ }^{10}$ \\ Mohammed AE Naiel," \\ Khaled A El-Tarabily (ID) ${ }^{12,13}$
}

'Department of Pathology, Faculty of Veterinary Medicine, Thamar University, Dhamar, Yemen; ${ }^{2}$ Laboratory of Regional Djibouti Livestock Quarantine, Abu Yasar international Est. 1999, Arta, Djibouti; ${ }^{3}$ Department of Medical Analysis, Princess Aisha Bint Al-Hussein College of Nursing and Medical Sciences, AlHussein Bin Talal University, Ma'an, 7I I I I, Jordan; ${ }^{4}$ Central Labs, King Faisal University, Al-Ahsa, Saudi Arabia; ${ }^{5}$ Department of Biochemistry, Faculty of Veterinary Medicine, Damanhour University, Damanhour, 225II, Egypt; 'Department of Pathology, Faculty of Veterinary Medicine, Alexandria University, Edfina, 22758, Egypt; ${ }^{7}$ Department of Theriogenology, Faculty of Veterinary Medicine, Zagazig University, Zagazig, 445I I, Egypt; ${ }^{8}$ Anti-Doping Lab Qatar, Doha, Qatar; 'Department of Pharmaceutical Sciences, the Pharmaceutical Research Institute, Albany College of Pharmacy and Health Sciences, Rensselaer, NY, 12144 , USA; ${ }^{10}$ Poultry Department, Faculty of Agriculture, Zagazig University, Zagazig, 445 I9, Egypt; " Animal Production Department, Faculty of Agriculture, Zagazig University, Zagazig, 44519, Egypt;

${ }^{12}$ Department of Biology, College of Science, United Arab Emirates University, Al-Ain, I555I, United Arab Emirates; ${ }^{13}$ Biosecurity and One Health Research Centre, Harry Butler Institute, Murdoch University, Murdoch, Western Australia, 6150, Australia

Correspondence: Khaled A El-Tarabily Email ktarabily@uaeu.ac.ae

\begin{abstract}
As a crucial organ, the lung is exposed to various harmful agents that may induce inflammation and oxidative stress, which may cause chronic or acute lung injury. Nigella sativa, also known as black seed, has been widely used to treat various diseases and is one of the most extensively researched medicinal plants. Thymoquinone (TQ) is the main component of black seed volatile oil and has been proven to have antioxidant, anti-inflammatory, and antineoplastic properties. The potential therapeutic properties of TQ against various pulmonary disorders have been studied in both in vitro and in vivo studies. Furthermore, the application of nanotechnology may increase drug solubility, cellular absorption, drug release (sustained or control), and drug delivery to lung tissue target sites. As a result, fabricating TQ as nanoparticles (NPs) is a potential therapeutic approach against a variety of lung diseases. In this current review, we summarize recent findings on the efficacy of TQ and its nanotypes in lung disorders caused by immunocompromised conditions such as cancer, diabetes, gastric ulcers, and other neurodegenerative diseases. It is concluded that TQ nanoparticles with antiinflammatory, antioxidant, antiasthma, and antitumor activity may be safely applied to treat lung disorders. However, more research is required before TQ nanoparticles can be used as pharmaceutical preparations in human studies.
\end{abstract}

Keywords: anticancer activity, antimicrobial activity, bioavailability, drug delivery, molecular potential, lung disease, nanoparticle, thymoquinone

\section{Introduction}

Over the last decade, the rising morbidity and mortality rates from acute and chronic lung diseases have become critical public health concerns worldwide. ${ }^{1}$ Trauma, air contamination, obesity, and multiple types of bacteria are the most common causes of pulmonary injury. Acute lung injury (ALI), known as acute respiratory distress syndrome (ARDS), is a pulmonary disorder marked by inflammation-associated lesions in various diseases associated with high mortality (between $25 \%$ and $40 \%$ in the USA) and morbidity (35-50\%) in both animals and humans worldwide. ${ }^{1}$ ARDS, is a potentially fatal infection caused by acute hypoxemic respiratory failure, bilateral convergence on chest radiography, and the low of left atrial blood pressure. ${ }^{2}$

Sepsis, smoke inhalation injury, near-drowning, acute pneumonia, and pulmonary hematoma are the most common causes of ARDS. ${ }^{3}$ Some of the most common chronic obstructive pulmonary diseases are asthma, bronchopulmonary dysplasia. ${ }^{3}$ Several in vivo animal models for chronic respiratory disorders such as allergic inflammation, 
bronchitis, airway remodeling, emphysema, and fibrosis have been developed, which are produced using ovalbumin, ${ }^{4}$ lipopolysaccharide (LPS), ${ }^{5}$ cigarette smoke, ${ }^{6}$ diesel exhaust, ${ }^{7}$ bleomycin, ${ }^{8}$ and silica. ${ }^{9}$ Biological studies have revealed that LPS is the leading cause of acute and chronic lung injury, derived from Gram-negative bacteria and pollution (mainly cigarette smoke). LPS induces severe lung inflammation, activation of interstitial resident macrophages, and the recruitment of neutrophils in the alveoli and airways of guinea pigs, rats, and mice. ${ }^{10,11}$ Despite the progress made in advanced supportive care, ARDS still has a high mortality rate.

There is a need for new approaches to affect certain pathological pathways and boost the immune responses in order to prevent, treat, and manage allergic and immunodeficiency diseases. Nigella sativa L. (family Ranunculaceae), known as black seed or black cumin, has been commonly used as a food ingredient and herbal medication to treat many inflammatory and allergic diseases in various countries, particularly in the Southwest Asian regions. ${ }^{12}$ Many reports have indicated its broad spectrum of potential therapeutic benefits, including bronchodilatory, immunomodulatory, antibacterial, hypotensive, antidiabetic, hepatoprotective, gastroprotective, neuroprotective, antihistaminic, anticancer, anti-inflammatory, and antioxidant effects. ${ }^{12-14}$ Most of its therapeutic benefits have been revealed to be related to the presence of thymoquinone (TQ), a primary active ingredient of $N$. sativa oil. ${ }^{15}$ The potential therapeutic properties and biological activity of TQ are presented in Figure 1.

The field of pulmonary drug delivery has grown tremendously since the mid-20th century and is now a multi-billion -dollar industry. Drug delivery for lung injuries differs depending on the target site. ${ }^{16}$ In recent decades, pulmonary inhalation has been considered a promising route for administering drugs, for treating not only local conditions but also systemic diseases such as diabetes. ${ }^{16}$ In asthma, the drug needs to be delivered to the upper airways; however, drug deposition deep in the lungs is required in alveolar lung diseases such as chronic obstructive pulmonary disease and idiopathic pulmonary fibrosis. ${ }^{17}$ Recently, many studies have revealed that inhaled nanoparticle-based therapeutics can immediately access all areas of the lung tissue, potentially improving the supply of medication to the target

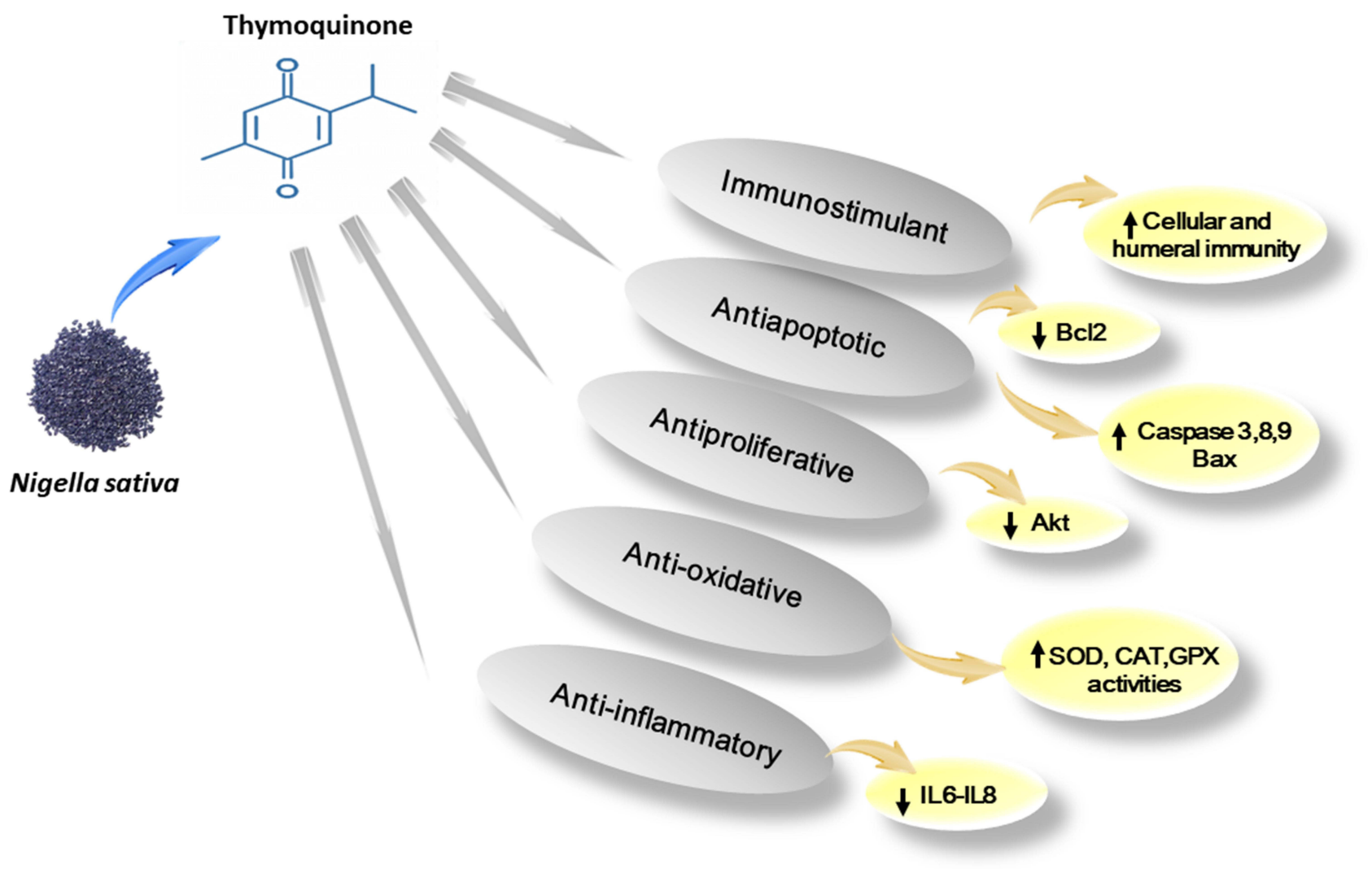

Figure I The molecular function of thymoquinone (TQ) pathways.

Abbreviations: Bcl2, B-cell lymphoma; Akt, protein kinase; SOD, superoxide dismutase; CAT, catalase; GPX, glutathione peroxidase; IL6-IL8, proinflammatory cytokines IL6, IL-8. 
cells. ${ }^{18,19}$ Moreover, nanoparticles (NPs) with a size in the range of 1 to $5 \mu \mathrm{m}$ are deposited deep in the lungs, while particles $>10 \mu \mathrm{m}$ are generally deposited in the oropharyngeal region. ${ }^{20}$ Targeted respiratory symptoms have been treated by many types of NPs, such as chitosan/tripolyphosphate NPs for the delivery of proteins to the lungs ${ }^{21}$ and antibody-coated NPs. ${ }^{22}$ Moreover, solid lipid NPs (SLNs) were used for the delivery of insulin to the lungs, ${ }^{23}$ as were insulin-loaded poly-butyl-cyanoacrylate NPs, ${ }^{24}$ while microencapsulated chitosan NPs were used for the delivery of pulmonary proteins. ${ }^{25}$

However, few studies investigating the therapeutic role of nano-TQ in preventing or treating lung diseases have been reported. A recently reported study showed that TQ poly-lactide-co-glycolic acid (PLGA)-polyvinyl alcohol NPs ameliorated pulmonary fibrosis in rats induced by bleomycin via the regulation of inflammatory cytokines and inducible nitric oxide synthase signaling. ${ }^{26}$ In the recent literature, there is evidence of TQ's therapeutic role in treating and controlling respiratory diseases and nano-TQ's involvement in the medical control of cancer, diabetes, gastric ulcer, and hepato- and neurotoxicity in the treatment of Huntington's disease-like syndrome. ${ }^{26}$ Based on the reviewed findings, it is anticipated that researchers will formulate suitable TQ-NPs to control and treat lung diseases.

\section{Acute Respiratory Distress Syndrome (ARDS)}

Lung injury might be induced in response to chemicals and environmental pollutants, including cigarette smoke, diesel exhaust, and silica, in addition to ovalbumin and LPS (Figure 2). LPS is found in the cell walls of Gramnegative bacteria and can elicit immune responses in humans and animals. ${ }^{27}$ LPS plays a critical role in bacterial pathogenesis because it can act as an immunomodulator and an immuno-stimulator. ${ }^{28}$ In addition, LPS is considered to be chemotactic for pathogen-associated molecular patterns and stimulate host inflammatory reactions. LPS was shown to elicit this response through binding to Toll-like receptor-4 (TLR-4). ${ }^{29}$

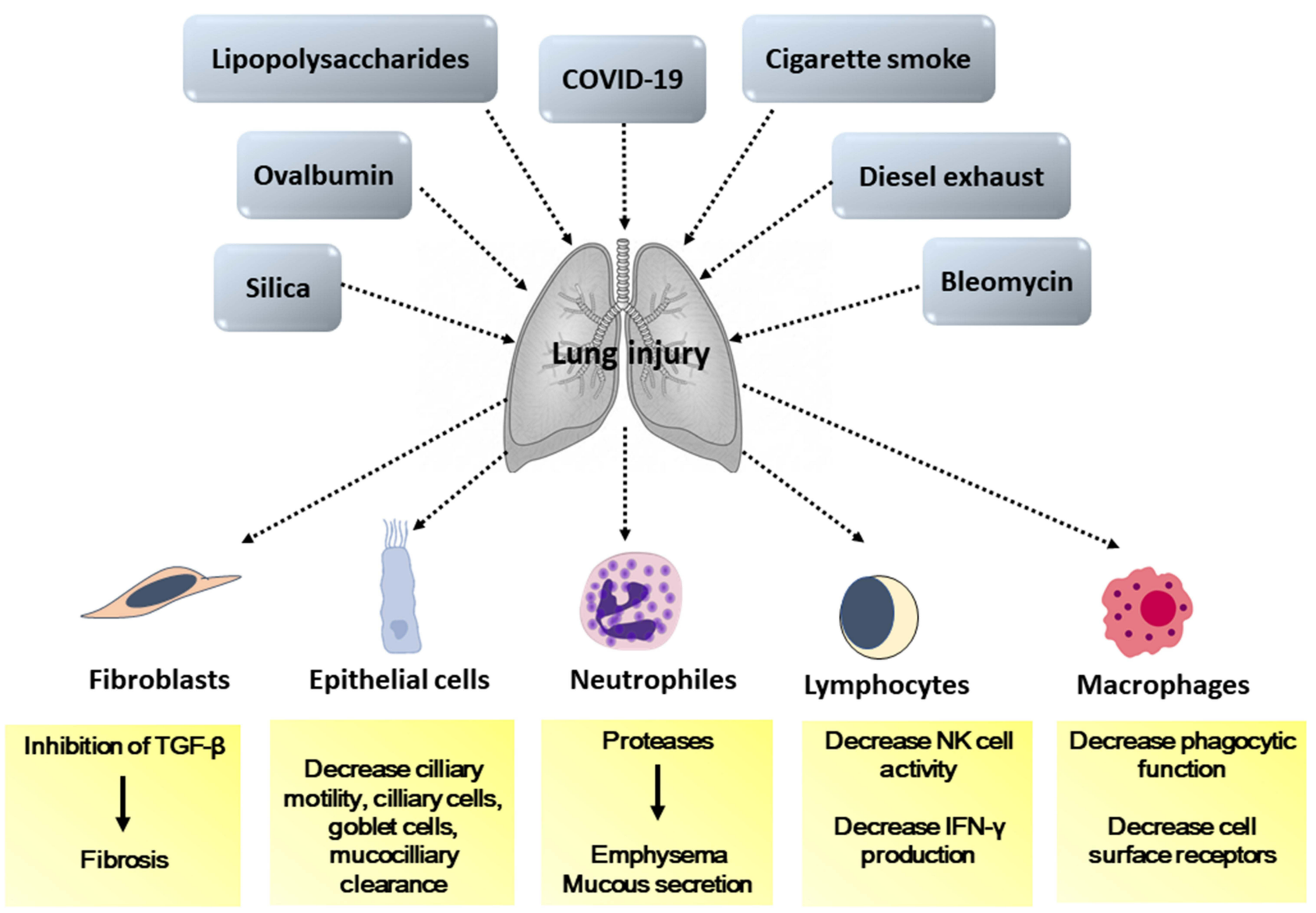

Figure 2 The pharmacological function of thymoquinone (TQ) as an anti-inflammatory agent in the prevention of lung disease. Abbreviations: TGF- $\beta$, transforming growth factor $\beta$ I; NK, natural killer cell activity; IFN- $\gamma$, interferon-gamma. 
Experimentally, intratracheal installation of mice with $10 \mu \mathrm{g}$ of LPS was found to initiate an inflammatory response represented by the infiltration of granulocytes, particularly neutrophils, into the extracellular matrix and the release of many pro-inflammatory mediators that play a fundamental role in lung injury. ${ }^{30}$ Epithelial cells can recognize LPS during pulmonary infection and play a crucial role in innate pulmonary immunity. ${ }^{31}$ Moreover, LPS recognition by TLR-4 was found to initiate the inflammatory response via the activation of master transcription factors, mainly nuclear factor- $\mathrm{kB}(\mathrm{NF}-\kappa \mathrm{B})$, and cytokines. $^{32}$

The cytokines are small proteins secreted by certain cells that affect other cells' behavior and regulate cellular immunity and inflammatory response. Some of them reduce inflammation and promote healing as antiinflammatory cytokines, whereas others induce certain disorders as pro-inflammatory cytokines. ${ }^{33}$

In one study, mice that received $30 \mathrm{mg} / \mathrm{kg}$ LPS intraperitoneally exhibited significant increases in the production of tumor necrosis factor- $\alpha(\mathrm{TNF}-\alpha)$ in their tissues. In addition, pretreatment of mouse macrophages with a low dose of LPS modulated LPS-dependent interleukin-6 (IL6) production in vitro. ${ }^{34}$ Similarly, LPS was reported to induce pro-inflammatory cytokines, including TNF- $\alpha$, IL6, IL-1, and IL-12, as well as nitric oxide. ${ }^{35}$

Acute viral pneumonia is a major cause of ARDS, but not enough is known about the viruses' interactions with the host immune response. ${ }^{36}$ Since 2003, there have been multiple significant coronavirus outbreaks, leading to epidemics such as severe acute respiratory syndrome, Middle East respiratory syndrome, and coronavirus disease 2019 (COVID-19). Since the initial outbreak of COVID-19 in Wuhan, China, in December 2019, coronavirus has dramatically affected the lives and health of people around the world. ${ }^{37}$ COVID-19 is highly infectious and can lead to fatal ARDS, ${ }^{38}$ which features the dysregulation of lung perfusion (cytokine storm) causing increased vascular permeability and severe disease. ${ }^{39}$

\section{Chronic Lung Injury}

Chronic lung disease, often recognized as bronchopulmonary dysplasia, occurs when an infected lung is damaged. The damaged lung tissue becomes inflamed and might break down, resulting in chest trauma. ${ }^{40}$ Chronic lung injury induced by the inhalation of or chronic exposure to LPS has been studied by many investigators, who have described lesions of chronic lung inflammation due to several factors. ${ }^{41,42}$ Moreover, chronic inhalation of grain dust containing LPS was shown to induce classic asthma and airflow obstruction. ${ }^{43}$ After exposure to a nebulized solution $(30 \mu \mathrm{g} / \mathrm{mL})$ of LPS, inflammatory cell infiltrates in guinea pig lungs were observed. The enlargement of alveoli, swelling of the alveolar walls, goblet cell hyperplasia in the airways, and accumulation of many inflammatory cells such as macrophages and neutrophils were also recorded. ${ }^{44}$

Furthermore, repetitive intratracheal instillation of LPS, twice a week for up to 5 weeks, was reported to lead to emphysema, fibrosis, and bronchial mucus cell hyperplasia in hamsters. The lungs of LPS-treated hamsters had moderate to severe bronchial mucus cell hyperplasia, as represented by many periodic acid-Schiff-stainable acid muco-substance cells such as glycoproteins, glycolipids, and mucins in tissues. The level of fibrosis was recorded after the last dose, and it was marked in the visceral pleura 6 months after LPS recovery. ${ }^{45}$ Mucous cell metaplasia in the tracheal-bronchial airways of rats was observed after daily injection with $0.05 \mathrm{~mL}$ of saline containing $5 \mathrm{mg}$ of LPS for 3 days. ${ }^{45}$

In addition, pigs in farms with long-term exposure to LPS-laden dust were found to have a pulmonary inflammatory response related to the proportional decline in lung function with irreversible and progressive lung injury. ${ }^{46}$ Moreover, the intranasal instillation of low-dose LPS at 1 $\mu \mathrm{g}$ per mouse, twice weekly for 20 weeks, led to pulmonary lesions in the form of emphysema and an increased number of macrophages, alveolar destruction, and neutrophil infiltration. Furthermore, IL- 6 and TNF- $\alpha$ were found to be significantly upregulated in plasma. ${ }^{47}$ Taken together, these findings reinforce the assertion that occupational susceptibility to inhaled LPS is a significant risk factor for emphysema in humans. Moreover, LPS-induced mechanisms of emphysema are due to activated macrophages. Activated macrophages and chemotactic neutrophils secrete proteinases, elastases, and cytokines, which attack the alveolar wall and capillary beds. ${ }^{40}$

\section{Protective Effects of TQ Against Lung Diseases}

Many investigators have focused on TQ as the main biologically active compound of $N$. sativa. Seeds of $N$. sativa are well known as the primary natural source of $\mathrm{TQ}{ }^{48}$ Small amounts of TQ were also detected in $N$. arvensis L. seeds. ${ }^{49}$ TQ is a key bioactive constituent of the volatile oil of different types of black seed ( $N$. sativa), caraway 
(Carum carvi), coriander (Coriandrum sativum), and nutmeg (Myristica fragrans). ${ }^{50}$

The therapeutic pathways by which TQ prevents lung disease as an anti-inflammatory agent are illustrated in Figure 2. TQ's anti-inflammatory effects, especially against airway and pulmonary inflammation, are achieved via decreases in the production of inflammatory mediators such as sodium nitrite, which elevates NF- $\mathrm{KB}$ and proinflammatory cytokines, 5-lipoxygenase, leukotriene, and eosinophils. ${ }^{51}$ Meanwhile, TQ inhibits the LPS-induced production of IL-1 $\beta$, IL- 6 , and IL-12, suggesting its potential to suppress pro-inflammatory cytokines. ${ }^{51}$

In mice, in which ARDS was found to be induced by diesel exhaust particles intratracheally, systemic inflammation was represented by leukocytosis, increased IL-6 levels, and reduced systolic blood pressure after 4 and 12 $h$. TQ's protective effect on the damaged lung was recognized via decreased platelet numbers and prothrombotic cascades, but not platelet aggregation. ${ }^{52}$

In another study, the effects of crude TQ in ARDS induced by LPS were examined. Pulmonary tissue pathology, serum levels of cytokines, and immunohistochemical analysis of tissue NF- $\mathrm{kB}$ expression revealed TQ's ameliorating properties. ${ }^{53}$ These were characterized by a reduction in perivascular and interstitial edema, thickening of interalveolar septa, and hyperplasia of bronchial-associated lymphoid tissue. ${ }^{53}$ An electron microscopy study revealed active pneumocytes in TQ-treated rats and decreased serum levels of IL- $1 \beta$ and TNF- $\alpha$, as well as the absence of NF- $\mathrm{KB}$ expression in the lung. ${ }^{53,54}$ Hence, Pourgholamhossein et $\mathrm{al}^{55}$ studied TQ's potential to alleviate lung fibrosis induced by the herbicide paraquat in mice. They found that TQ had a preventive effect against lung fibrosis by inhibiting oxidative stress and downregulating the expression of pro-fibrotic genes. TQ was also found to enhance the efferocytotic/ phagocytic ability, antagonizing the effects of cigarette smoke extract and LPS on phagocytosis. ${ }^{55}$ Simultaneously, the sphingosine-1-phosphate receptor 5 genes were shown to protect bronchial epithelial cells from cigarette smokeinduced apoptosis. ${ }^{56}$

In the same context, Keyhanmanesh et $\mathrm{al}^{57}$ found that the treatment of ovalbumin-sensitized guinea pigs with TQ significantly improved their pathological changes in the lung and decreased their IL-4 levels, but increased their interferongamma (IFN- $\gamma$ ) levels. These results proved the preventive role of TQ against lung inflammation in guinea pigs. ${ }^{57} \mathrm{In}$ addition, Suddek et $\mathrm{al}^{58}$ stated that TQ protected against cyclophosphamide-induced pulmonary damage and suggested its ameliorative role against oxidative stress and inflammation induced by the pathogenesis through the attenuation of serum TNF- $\alpha$ in rats. TQ's protective function may be attributable to its ability to inhibit attenuated allergic airway inflammation by reducing eosinophil penetration and goblet cell hyperplasia. ${ }^{59}$ TQ was also shown to greatly decrease the production of IL-4, IL-1, and IL-35 while suppressing IFN- $\gamma$ production in bronchoalveolar lavage fluid. ${ }^{60}$

These changes were revealed to be associated with the inhibition of prostaglandin D2 production and cyclooxygenase-2 protein expression. ${ }^{60}$ Similarly, TQ was found to attenuate the inflammatory response in mast cells induced by LPS in a rat basophil cell line by modulating NF- $\mathrm{KB}$ binding and TNF- $\alpha$ transcription. ${ }^{61}$ TQ also induced a significant rise in surfactant protein $\mathrm{D}$ expression in the lung tissue of toluene-treated rats. ${ }^{62}$

The local administration of TQ for experimentally induced rhinosinusitis in rats showed that TQ had a promising bioactive effect. It was concluded that its histopathological effect was equivalent to that achieved upon the use of antibiotics. ${ }^{63}$ In the same context, Kanter ${ }^{64}$ demonstrated that TQ ameliorated allergic rhinitis events, had a marked anti-apoptotic effect, and reduced lung injury induced by chronic toluene exposure. The inhibitory effect of local TQ on corneal neovascularization was also studied in rats and a comparison of its efficacy with that of triamcinolone (synthetic corticosteroid) was performed. ${ }^{65}$ It was concluded that the intranasal installation of TQ might affect chemical (silver nitrate) burninduced corneal neovascularization by suppressing many oxidative and inflammatory mediators. ${ }^{65}$

TQ showed a major effect of preventing pulmonary vascular damage caused by Escherichia coli-derived LPS by inducing substantial reductions in serum IL- $1 \beta$ and TNF- $\alpha$ levels in rats. ${ }^{54}$ In addition, levosimendan and TQ were found to attenuate lung injury after myocardial ischemia-reperfusion in rats. ${ }^{66}$ Based on the above-mentioned results, TQ effectively attenuated lung diseases through downregulating the lung NF- $\mathrm{KB}$ pathway and subsequently decreasing cytokine and chemokine production, thereby alleviating the inflammatory processes of lung diseases.

\section{TQ Nanoformulations for Improved Oral Bioavailability}

There is a real desire among researchers for TQ to progress from the bench to clinical testing for use against cancer, lung diseases, and other chronic diseases. However, the transition of TQ into clinical trials is being 
impeded by formulation issues due to its physicochemical properties and the route of administration. ${ }^{67}$ In terms of TQ's physicochemical properties, it can be summarized as a fat-soluble molecule with a solubility range of 0.549 $0.740 \mathrm{mg} / \mathrm{mL}$ in aqueous medium over $24-72 \mathrm{~h}^{68}$ Furthermore, TQ is extremely unstable in aqueous solutions due to the strong influence of $\mathrm{pH}$ and light, with the latter having a stronger destabilizing effect. ${ }^{69}$ TQ taken orally can induce chemical and enzymatic changes in its composition in the gastrointestinal tract, as well as extensive hepatic first-pass metabolism disorders. ${ }^{70}$ Consequently, oral administration and the use of pure aqueous solutions as medicinal vehicles for TQ formulations fail to achieve the required therapeutic efficacy of TQ. ${ }^{71}$ In this context, the use of organic and aqueous solvents as well as nanocarriers appeared to be viable solutions. $^{72}$

In this respect, NP drug delivery systems have recently been investigated as a promising option for vehicles for delivering TQ. An essential task in nanomedical research is to design and develop multifunctional NP complexes that can deliver diagnostic and therapeutic agents to targeted sites. ${ }^{73}$ Nanomedicine can provide drug targeting, surface conjugation, and improve bioavailability. ${ }^{74} \mathrm{TQ}$ has great biological potential and a nanoformulation of TQ can enhance these activities. TQ nanomaterials can easily penetrate biological membranes and provide the sustained release of TQ, as detailed in reviews by Badary et a ${ }^{75}$ and Rathore et al. ${ }^{76}$ The biological activities and therapeutic potential of TQ's nanoforms against pulmonary diseases are presented in Table 1 and Figure 3.

\section{Broad-Spectrum Benefits of TQ}

\section{Anticancer Activities}

Cancer is generally a genetic disease induced by changes to genes that regulate cell functions, especially cell growth and division. ${ }^{77}$ Mutations that can potentially lead to cancer can be passed down from the parents or caused by various types of DNA damage triggered by certain environmental stressors. ${ }^{78}$ These can include environmental exposure to cancer-causing substances, such as the chemicals in tobacco smoke, as well as radiation, such as ultraviolet rays from the sun. ${ }^{79}$ Genetic damage that leads to cancer tends to affect three main types of gene: protooncogenes, tumor suppressor genes, and DNA repair genes. ${ }^{80}$ A representative example of a tumor suppressor gene is p53, which plays a vital role in controlling cell division and cell death through regulating the accumulation of proteins in the nucleus. Mutations in this gene may cause cancer cells to grow and spread in the body. ${ }^{81}$

The mechanisms of action of TQ include activation of the p53 gene and its downstream effector p $21^{\mathrm{WAFI}}$ and reduction of the concentration of the anti-apoptotic protein B-cell lymphoma 2 (Bcl-2). However, TQ's antiproliferative effects were shown to be achieved via the induction of p53-independent apoptosis and the activation of caspase-8, -9 , and $-3 .^{82}$ Activated caspase- 8 prompts mitochondria to release cytochrome $\mathrm{C}$. TQ was found to modulate the Bcl2-associated $\mathrm{X}$ protein $(\mathrm{Bax}) / \mathrm{Bcl} 2$ ratio by upregulating pro-apoptotic Bax and downregulating anti-apoptotic Bcl2 proteins in p53 ${ }^{- \text {null }}$ HL-60 cells during apoptosis. ${ }^{83}$ These results clarified TQ's pharmacological effects and identified it as a chemopreventive or chemotherapeutic agent to treat $\mathrm{p} 53$-deficient cancers.

Formulated TQ-NPs were shown to exhibit a significant delay in the release of TQ, implying greater effectiveness against tumor cells. ${ }^{84}$ In addition, TQ-NPs exhibited a major improvement in cytotoxicity against MCF-7 cells. This was particularly regulated through increased apoptosis, as shown by a cell cycle study, annexin V staining, and caspase-3 determination, which reinforced the cytotoxicity of TQ-NPs, as described by Fahmy et al. ${ }^{84}$ In the same context, TQ-loaded NP emulsion was shown to be more effective than free TQ against the growth of MDA-MB-231 breast cancer cells. ${ }^{85}$ In addition, TQ-loaded liposomes inhibited the MCF-7 breast cancer cell line. ${ }^{86}$ Likewise, MCF-7 cells were shown to be more sensitive to TQ- beta-cyclodextrin (CD) NPs than to free TQ, with an $\mathrm{IC}_{50}$ of $4.70 \pm 0.60 \mu \mathrm{M}$ for TQ-CD but $24.09 \pm 2.35 \mu \mathrm{M}$ for free TQ. ${ }^{87}$

Additionally, PLGA-NPs loaded with paclitaxel and TQ exhibited higher anticancer activity against MCF-7 cells and alleviated paclitaxel's toxic effects compared with the free drugs. ${ }^{88}$ Similarly, the proliferation of the MCF-7 cell line was found to be controlled by crude TQ, and the nano-TQ therapy of which resulted in $50 \%$ cell death. ${ }^{89}$ Moreover, TQ-loaded nanostructured lipid carriers (TQ-NLCs) were very cytotoxic to breast cancer MDA-MB-231 cells, which was achieved through cell cycle arrest and the induction of apoptosis. ${ }^{62}$ In another study, TQ-encapsulated NPs significantly increased the expression of miR-34a through p53, leading to the downregulation of Rac1 expression, followed by actin depolymerization, thereby disrupting the actin cytoskeleton and retarding the migration of the human mammary carcinoma 


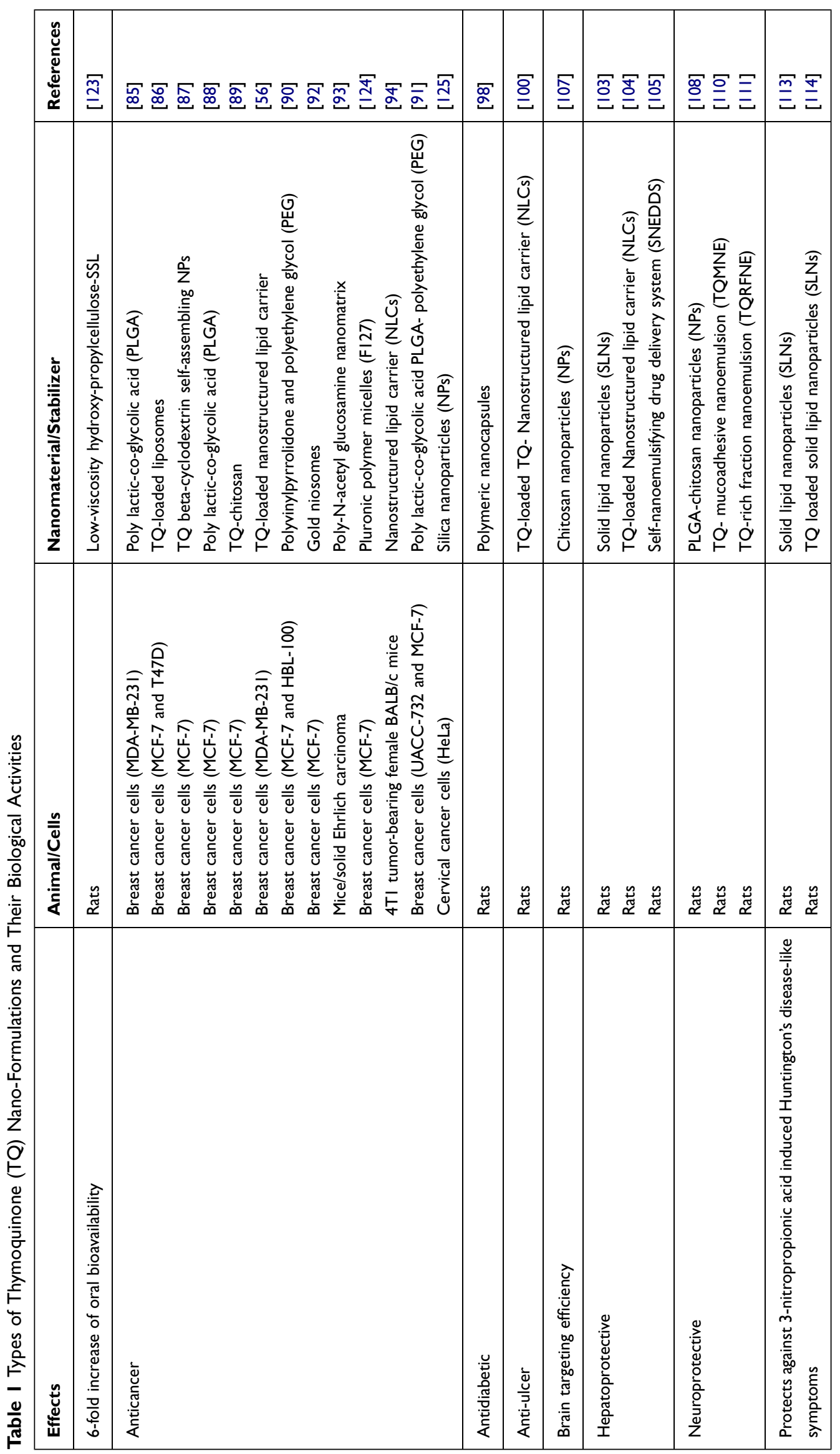




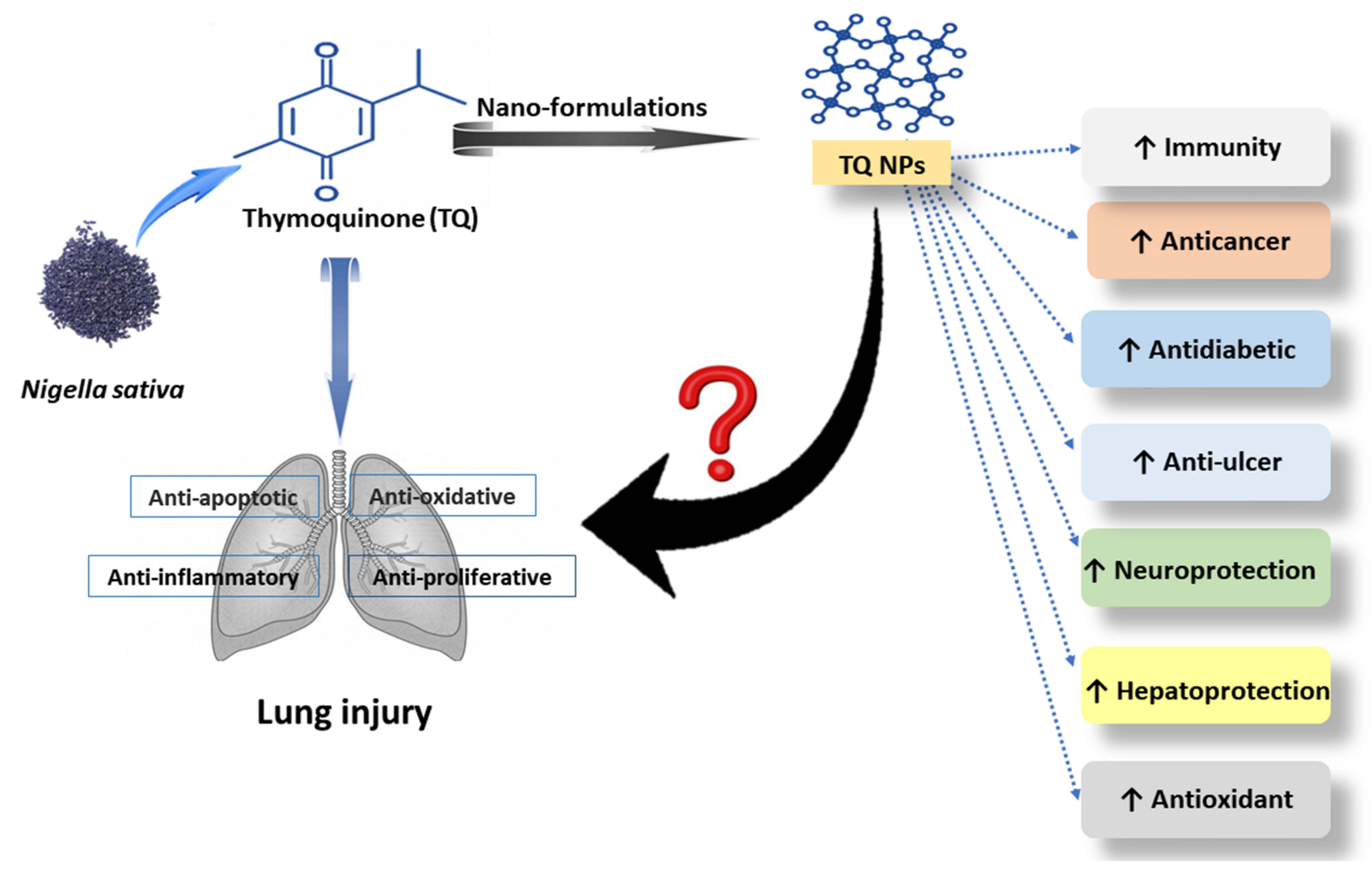

Figure 3 Thymoquinone (TQ) nanoformulations' bioavailability, pharmacokinetics, and pharmacodynamic prospects against lung diseases.

cell lines MCF-7 and HBL-100. ${ }^{90}$ In addition, Ahmad et $\mathrm{al}^{91}$ reported the selective cytotoxic effects of synthesized TQ-PLGA-polyethylene glycol (PEG) NPs in tamoxifen-resistant breast cancer cells (UACC-732). ${ }^{91}$

Moreover, Rajput et $\mathrm{al}^{92}$ stated that multi-lamellar gold niosomes helped TQ to overcome Akt-induced drug resistance in MCF-7 cells. ${ }^{92}$ Moreover, El-Ashmawy et $\mathrm{al}^{93}$ investigated the use of TQ in combination with the chemotherapeutic agent doxorubicin (DOX) in F2 gel to control tumor progression in Ehrlich solid tumor-bearing mice. The nano-combination of TQ and DOX showed significant reductions in tumor volume, cardiac markers, tumor Bcl-2, and p53 upregulation compared with free conventional therapies. Moreover, co-treatment with DOX+TQ+F2 gel achieved superior effects compared with all other treatments, with less DOX cardiotoxicity. ${ }^{93}$

In addition, Ong et $\mathrm{al}^{94}$ investigated the anticancer properties of TQ using NLCs in breast cancer cell line (4T1) tumor-bearing female BALB/c mice. The use of NLC as a carrier enhanced TQ's therapeutic effects by increasing the survival rate of mice via modulating Bcl-2 and caspase- 8 in the intrinsic apoptotic pathway. The metastasis of $4 \mathrm{~T} 1$ was also restricted to the lung, as evidenced by the downregulation of matrix metalloproteinase $2 .^{94}$

Briefly, nanoformulations of TQ, either alone or in synergy with chemotherapeutic agents, have increased bioavailability and apoptotic potential against various types of cancer, mainly targeting the intrinsic apoptotic pathway.

\section{Antidiabetic and Antiulcer Activities}

Diabetes is a long-term health condition that influences cells' ability to generate energy from food. The majority of consumed food is converted into glucose and released into the bloodstream. ${ }^{95}$ When blood glucose levels rise, it induces pancreatic cells to release insulin stored as glycogen. ${ }^{96}$ Natural bioactive compounds exhibit a powerful antidiabetic effect, which overcomes oxidative stress. $^{97}$

Rani et $\mathrm{al}^{98}$ prepared polymeric nanocapsules (NCs) of TQ and metformin using a gum rosin nanoprecipitation method. ${ }^{98}$ TQ $(20,40$, and $80 \mathrm{mg} / \mathrm{kg})$, metformin $(150 \mathrm{mg} /$ $\mathrm{kg})$, and their nanoformulations $(20,40$, and $80 \mathrm{mg} / \mathrm{kg}$ for TQ and $80 \mathrm{mg} / \mathrm{kg}$ for metformin) were orally administered for 21 successive days in type 2 diabetic rats. The 
nanoformulations significantly decreased the rats' blood glucose levels and glycated hemoglobin and improved their lipid profile compared with the findings in diabetic and control rats. ${ }^{98}$ Interestingly, TQ-NCs (containing 10, 20 , and $40 \mathrm{mg}$ ) produced a dose-dependent antihyperglycemic effect. Moreover, TQ-NCs produced a better antihyperglycemic effect in type 2 diabetic rats than TQ alone..$^{98}$

The gastric mucosa can suffer ulceration due to several factors, but some natural products were shown to exhibit a strong protective effect against ulceration. ${ }^{99}$ The use of TQ-NLCs against ethanol-induced ulcers was evaluated by monitoring the mucus content, hydrogen concentration, and biochemical and histochemical parameters. It was concluded that TQ loading into the NLCs significantly improved the gastroprotective effects. Immunohistochemical results also revealed that the TQNLCs inhibited ulcer formation compared with TQ $(60 \mathrm{mg} / \mathrm{kg})$ administered orally in rats. ${ }^{100}$ Moreover, recently, gastric histopathological examination of animals with alcohol-induced gastric ulcers showed the possible role of TQ-loaded coconut oil nanostructure (NLC) in ameliorating ulcer formation. ${ }^{101}$

In summary, TQ encapsulation within nanostructures was discovered to more effectively spread the administered drug when delivered orally, resulting in protective effects against ulcers.

\section{Hepatoprotective Activities}

The liver plays a central role in all metabolic processes in the body. Therefore, hepatocytes' protection against different environmental xenobiotics is of great importance. ${ }^{102}$ Numerous studies evaluating the protective effects of nano-TQ against hepatotoxicity have thus been performed. Singh et $\mathrm{al}^{103}$ formulated and characterized solid lipid nanoparticles (SLNs) of TQ (TQ-SLNs) to treat liver cirrhosis. The TQ-SLN formula caused a nearly 5-fold increase in bioavailability compared with free TQ. It achieved significant decreases in serum biomarker enzymes such as alanine transaminase, aspartate transaminase (AST), and alkaline phosphatase (ALP), compared with a control and a marketed formulation $\left(\right.$ SILYBON $\left.^{\circledR}\right)$, against paracetamol-induced liver cirrhosis.

Moreover, using lipid NPs, Elmowafy et al ${ }^{104}$ prepared TQ-NLCs with high-speed homogenization followed by ultrasonication in vitro. There was a significant decline in hepatic malondialdehyde, reduced glutathione, and improved hepatic architecture. This study proved the antioxidant efficacy of TQ-NLCs in hepatic protection. Owing to TQ's low aqueous solubility and bioavailability, Kalam et $\mathrm{al}^{105}$ developed a self-nano-emulsifying drug delivery system (SNEDDS) of TQ to enhance its bioavailability and hepatoprotective effects. TQ's relative bioavailability was enhanced 3.87-fold by optimized SNEDDS compared with that with TQ suspension. ${ }^{105}$

\section{Neuroprotective Activities}

Multiple natural products have been used as protective agents against different neurotoxicants and neural diseases. ${ }^{106}$ For example, an ionic gelation method of chitosan NPs of TQ was established and used for brain targeting via intranasal instillation. The results showed that TQ-chitosan NPs exhibited more brain targeting than conventional TQ. ${ }^{107}$ This strongly supported the neuroprotective activity of TQ.

In another study, TQ-PLGA-chitosan NPs were intranasally instilled and evaluated for their neuroprotective efficacy in a rat cerebral ischemia-reperfusion model. ${ }^{108}$ Biochemical measurements revealed that the TQ-PLGAchitosan NPs significantly reduced lipid peroxidation but elevated reduced glutathione, catalase, and superoxide dismutase in rats with middle cerebral artery occlusion. As such, the intranasal delivery of TQ-loaded PLGA-chitosan NPs to the brain could be applied to achieve neuroprotective effects and treat cerebral ischemia. ${ }^{108}$

The inability of beneficial agents to reach the central nervous system (CNS) limits the efficacy of noninvasive therapy for neurological diseases. Since most CNS medications cannot penetrate the brain parenchyma due to the blood-brain barrier, overcoming this barrier has been one of the most important obstacles to progress in neurological therapeutics. ${ }^{109}$ To date, several different forms of nanomaterials have been developed and applied to treat neurological diseases, including liposomes, micelles, polymeric NPs, carbon nanotubes, quantum dots, and metallic NPs. ${ }^{109}$

In this context, TQ-mucoadhesive nanoemulsion was found to improve neurobehavioral activity (locomotor and grip strength) in rats with cerebral ischemia due to middle cerebral artery occlusion. ${ }^{110}$ Excessive amyloid- $\beta$ accumulation due to abnormal amyloid- $\beta$ precursor protein processing is crucial to the pathogenesis of Alzheimer's disease. ${ }^{111}$ TQ-rich fraction nanoemulsions were found to decrease the levels of amyloid- $\beta 40$ and $-\beta 42$ by modulating amyloid- $\beta$ precursor protein processing, upregulating insulindegrading enzyme and low-density-lipoprotein receptorrelated protein 1 , and downregulating $\beta$-secretase 1 and 
advanced glycation end products (RAGE) in response to the consumption of a high-fat/cholesterol diet in rats. ${ }^{111}$

In conclusion, TQ nanoscale drug carriers allow the successful delivery of drugs through the blood-brain barrier, overcoming the challenges associated with treating the CNS. Furthermore, TQ encapsulated by nanocarriers should penetrate deeper into target sites, thus avoiding degradation.

\section{Protection Against Huntington's Disease- Like Symptoms}

Researchers have identified four HDL syndromes, called Huntington disease-like 1 to 4 (HDL1-4). These progressive brain disorders are differentiated by uncontrollable movements, emotional problems, and a loss of thinking ability. ${ }^{112}$

Ramachandran and Thangarajan ${ }^{113,114}$ created SLNs encapsulating TQ (TQ-SLNs) and studied their effects on 3-nitropropionic acid-induced Huntington's disease-like symptoms in Wistar rats. The TQ-SLNs significantly restored the antioxidant defense system and alleviated the anticholinergic effect induced by 3-nitropropionic acid. ${ }^{113,114}$ These researchers suggested that supplementation with a low dose of TQ-SLN was highly efficient at attenuating behavioral, biochemical, and histological modifications in the HD model created by exposure to 3-nitropropionic acid. ${ }^{113,114}$

The limited studies performed to date clearly indicate the need for progress with nanoparticulate formulations of TQ, which have the potential to increase therapeutic effectiveness at lower doses in order to counteract the striatal assaults and motor complications shown in 3-NP neurotoxicity. Consequently, TQ-SLNs may be recommended as a promising formulation for treating Huntington's disease.

\section{Immunomodulatory Aspects of TQ}

Recently, it has been revealed that some COVID-19 cases requiring intensive care exhibited high concentrations of pro-inflammatory cytokines, including $\mathrm{TNF} \alpha$ (tumor necrosis factor-alpha) and IL-6, as well as lymphopenia with ARDS. ${ }^{115}$ As high IL-6 levels were found to be related to the severity of respiratory diseases, ${ }^{116}$ a reduction in IL-6 might be useful therapeutically. However, it is critical to choose the correct time for therapy, which, if delayed, is both ineffective and detrimental. TQ was found to be effective in downregulating or reducing inflammatory responses, such as those associated with IL-1, IL-6, IL-10, IL-18, TNF- $\alpha$, and NF- $\kappa B .{ }^{117}$

Several recent reports have indicated that TQ reduces the levels of 5-lipoxygenase, leukotriene B4, C4, and Th2 cytokines in bronchoalveolar lavage (BAL) fluid with significant increments of eosinophilia and goblet cells in lung tissue. ${ }^{116}$ In addition, TQ was found to alleviate the mRNA expression of inducible nitric oxide synthase and transforming growth factor $\beta 1$ (TGF- $\beta 1) .{ }^{118}$ The antiinflammatory potential of TQ might be related to the upregulation of heme oxygenase-1 (HO-1) in human keratinocytes $(\mathrm{HaCaT})$, which is stimulated by nuclear factor (NF) by ROS-mediated phosphorylation of protein kinase $\mathrm{B}(\mathrm{PKB})$ and protein kinase alpha $(\mathrm{PK} \alpha) .{ }^{119}$ Thus, it indirectly antagonizes the side effects caused by an increase in ROS level. ${ }^{120}$ The antioxidant properties of TQ may be due to the redox potential of the quinone structure and the unlimited ability of TQ to cross substantial barriers to cellular niches. ${ }^{121}$

The clinical findings mentioned above indicate that TQ is an important immunomodulatory agent in both cell- and antibody-mediated immune systems. Furthermore, TQ was shown to induce phagocytic reactions, increase antibody levels, and promote immunoglobulin hemagglutination after exposure to pesticide toxicity. ${ }^{122}$ Moreover, TQ was shown to decrease the levels of T- and B-lymphocyte receptors, innate cell markers, and islet cell antibodies in autoimmune disorders. As such, TQ is highly anticipated to become a successful treatment for lung immune disorders.

\section{Remarks and Future Directions}

The present review provides insight into TQ's therapeutic potential against various diseases, particularly those associated with lung injury. Since ancient times, TQ as a natural molecule found in many plant species has been used for pharmacological purposes and considered to be safe. TQ's low toxicity confers enormous potential for consumption as food, pharmacological applications, therapeutic development, and pharmaceutical benefits for human use. TQ has been recommended for pharmacological usage as a nutraceutical, prophylactic, or adjuvant, for chronic diseases with limited persistent inflammation and side effects associated with oxidative stress.

Recent molecular pharmacology studies have attributed TQ's therapeutic effects to its ability to modulate enzymatic, apoptotic, cell signaling pathways, transcription factors, numerous receptors, and ion channels. The 
antimicrobial, antiviral, and pharmacological modes of action inherent in its medical application warrant further scientific investigations of TQ's therapeutic potential.

There is a need for further investigation of the synergistic effects of TQ and other pharmacological products or drugs. The results of this investigation can provide the primary basis for the usage of TQ and other pharmacological products or drugs in treatment of infectious diseases induced by multiple factors using one medication or multiple therapeutic goals.

Although the results obtained from laboratory work are promising, there is a clear need to examine TQ's translational properties. For example, there is a need to understand the selective antibacterial and antiviral effects of TQ. However, to achieve the potential benefits of these natural molecules and their nanoscale forms, clinical trials are required to convert the in vitro indications into clinical benefits.

\section{Conclusion}

This current report describes TQ's biological properties and reveals its medicinal potential for treating various diseases, including respiratory infectious diseases, cancer, diabetes, hepatic cirrhosis, and neurodegenerative disorders such as Huntington's disease. TQ reduces the intensity of ARDS by promoting lung antioxidant and anti-inflammatory responses to infection.

Nano-TQ was found to be more effective than crude TQ in ameliorating numerous inflammatory diseases, so it may be of value in preventing and treating lung diseases. Overall, existing evidence clearly shows that TQ in nanoform can achieve efficient delivery to target tissue and alleviate lung damage. Nano-TQ's low toxicity has attracted considerable commercial interest worldwide for use in pharmacological applications, and for achieving medicinal benefits and pharmaceutical progress. The existing evidence raises the possibility of its usage as a nutraceutical, prophylactic, or adjuvant for chronic illnesses induced by low-grade persistent oxidative stress and inflammation.

Thus, we encourage researchers to formulate nano-TQ with a suitable size for each type of lung injury and investigate its effects against various lung injuryassociated diseases by evaluating the following cellular molecules: TLR and its associated pathway; RAGE and its ligands; NF- $\mathrm{kB}$, activator protein 1; matrix metalloproteinases; inflammatory markers including interleukins; TNF- $\alpha$, transforming growth factor- $\beta$; inducible nitric oxide synthases; tissue repair factors such as epidermal growth factor, keratinocyte growth factor or hepatic growth factor; vascular endothelial growth factor; and antioxidant enzymes such as superoxide dismutase, catalase, glutathione reductase, glutathione peroxidase, and glutathione S-transferase.

\section{Acknowledgments}

The authors are grateful for support from their respected universities and institutes. K.A. El-Tarabily would like to thank the library at Murdoch University, Australia for the valuable online resources and comprehensive databases.

\section{Author Contributions}

All authors made substantial contributions to conception and design, acquisition of data, or analysis and interpretation of data; took part in drafting the article or revising it critically for important intellectual content; agreed to submit to the current journal; gave final approval of the version to be published; and agree to be accountable for all aspects of the work.

\section{Funding}

This project was funded by Abu Dhabi Research Award (AARE2019) for Research Excellence-Department of Education and Knowledge (ADEK-007; Grant \#: 21S105) to Prof. Khaled El-Tarabily.

\section{Disclosure}

The authors declare that they have no conflicts of interest for this work.

\section{References}

1. Tong L, Bi J, Zhu X, et al. Keratinocyte growth factor-2 is protective in lipopolysaccharide-induced acute lung injury in rats. Respir Physiol Neurobiol. 2014;201:7-14. doi:10.1016/j.resp.2014.06.011

2. Xiao M, Zhu T, Zhang W, et al. Emodin ameliorates LPS-induced acute lung injury, involving the inactivation of NF- $\mathrm{KB}$ in mice. Int J Mol Sci. 2014;15:19355-19368. doi:10.3390/ijms151119355

3. Ware LB, Matthay MA. The acute respiratory distress syndrome. $N$ Engl $J$ Med. 2000;342:1334-1349. doi:10.1056/ NEJM200005043421806

4. Hutson PA, Church MK, Clay TP, Miller P, Holgate ST. Early and late-phase bronchoconstriction after allergen challenge of nonanesthetized guinea pigs. Am Rev Respir Dis. 1988;137:548-557. doi:10.1164/ ajrccm/137.3.548

5. Savov JD, Brass DM, Berman KG, McElvania E, Schwartz DA. Fibrinolysis in LPS-induced chronic airway disease. Am J Physiol Lung Cell Mol Physiol. 2003;285:L940-L948. doi:10.1152/ ajplung.00102.2003

6. Hele D. First siena international conference on animal models of chronic obstructive pulmonary disease; 2001 Sept-30-Oct 2; Certosa di Pontignano, University of Siena, Italy. Respir Res. 2001;3:12. doi:10.1186/rr161 
7. Kobayashi T. Exposure to diesel exhaust aggravates nasal allergic reaction in guinea pigs. Am $J$ Respir Crit Care Med. 2000;162:352-356. doi:10.1164/ajrccm.162.2.9809035

8. Coker RK, Laurent GJ, Shahzeidi S, et al. Transforming growth factors-beta 1,-beta 2, and-beta 3 stimulate fibroblast procollagen production in vitro but are differentially expressed during bleomycin-induced lung fibrosis. Am J Pathol. 1997;150:981.

9. Onclinx C, De Maertelaer V, Gustin P, Gevenois PA. Elastaseinduced pulmonary emphysema in rats: comparison of computed density and microscopic morphometry. Radiology. 2006;241:763-770. doi:10.1148/radiol.2413051456

10. Gordon T, Balmes J, Fine J, Sheppard D. Airway oedema and obstruction in guinea pigs exposed to inhaled endotoxin. $\mathrm{Br} J$ Ind Med. 1991;48:629-635. doi:10.1136/oem.48.9.629

11. Ulich TR, Yi ES, Yin S, Smith C, Remick D. Intratracheal administration of endotoxin and cytokines: VII. The soluble interleukin-1 receptor and the soluble tumor necrosis factor receptor II (p80) inhibit acute inflammation. Clin Immunol Immunopathol. 1994;72:137-140. doi:10.1006/clin.1994.1117

12. Abd El-Hack ME, Alagawany M, Farag MR, Tiwari R, Karthik K, Dhama K. Nutritional, healthical and therapeutic efficacy of black cumin (Nigella sativa) in animals, poultry and humans. Int $J$ Pharmacol. 2016;12:232-248. doi:10.3923/ ijp.2016.232.248

13. Abd El-Hakim YM, Al-Sagheer AA, Khafaga AF, Batiha GE, Arif M, Abd El-Hack ME. Nigella sativa supplementation in ruminant diets: production, health, and environmental perspectives. In: Fawzy Ramadan M editor. Black Cumin (Nigella sativa) Seeds: Chemistry, Technology, Functionality, and Applications. Food Bioactive Ingredients. Springer; 2021:245-264. doi:10.1007/978-3-030-48798-0_17.

14. Gado AR, Ellakany HF, Elbestawy AR, et al. Herbal medicine additives as powerful agents to control and prevent avian influenza virus in poultry-a review. Ann Anim Sci. 2019;19:905-935. doi:10.2478/aoas-2019-0043

15. El-Far AH, Korshom MA, Mandour AA, El-Bessoumy AA, ElSayed YS. Hepatoprotective efficacy of Nigella sativa seeds dietary supplementation against lead acetate-induced oxidative damage in rabbit-purification and characterization of glutathione peroxidase. Biomed Pharmacother. 2017;89:711-718. doi:10.1016/j.biopha.2017.02.044

16. Mahapatro A, Singh DK. Biodegradable nanoparticles are excellent vehicle for site directed in vivo delivery of drugs and vaccines. J Nanobiotechnol. 2011;9:55. doi:10.1186/1477-31559-55

17. van Rijt SH, Bein T, Meiners S. Medical nanoparticles for next generation drug delivery to the lungs. Eur Respir Soc. 2014;44:765-774. doi:10.1183/09031936.00212813

18. Babu A, Templeton AK, Munshi A, Ramesh R. Nanoparticlebased drug delivery for therapy of lung cancer: progress and challenges. J Nanomater. 2013;2013:863951. doi:10.1155/2013/ 863951

19. Lee W-H, Loo C-Y, Traini D, Young PM. Inhalation of nanoparticle-based drug for lung cancer treatment: advantages and challenges. Asian $J$ Pharm Sci. 2015;10:481-489. doi:10.1016/j.ajps.2015.08.009

20. Malcolmson R, Embleton JK. Dry powder formulations for pulmonary delivery. Pharmaceut Sci Tech Today. 1998;1:394-398. doi:10.1016/S1461-5347(98)00099-6

21. Grenha A, Seijo B, Remunán-López C. Microencapsulated chitosan nanoparticles for lung protein delivery. Eur J Pharm Sci. 2005;25:427-437. doi:10.1016/j.ejps.2005.04.009

22. Kolhar P, Anselmo AC, Gupta V, et al. Using shape effects to target antibody-coated nanoparticles to lung and brain endothelium. Proc Natl Acad Sci USA. 2013;110:10753-10758. doi:10.1073/ pnas. 1308345110
23. Liu J, Gong T, Fu H, et al. Solid lipid nanoparticles for pulmonary delivery of insulin. Int J Pharm. 2008;356:333-344. doi:10.1016/ j.ijpharm.2008.01.008

24. Zhang Q, Shen Z, Nagai T. Prolonged hypoglycemic effect of insulin-loaded polybutylcyanoacrylate nanoparticles after pulmonary administration to normal rats. Int $J$ Pharm. 2001;218:75-80. doi:10.1016/s0378-5173(01)00614-7

25. Al-Qadi S, Grenha A, Carrión-Recio D, Seijo B, Remuñán-López C. Microencapsulated chitosan nanoparticles for pulmonary protein delivery: in vivo evaluation of insulin-loaded formulations. $J$ Control Release. 2012;157:383-390. doi:10.1016/j.jconrel.2011.08.008

26. Saghir SA, Al-Gabri NA, Khafaga AF, et al. ThymoquinonePLGA-PVA nanoparticles ameliorate bleomycin-induced pulmonary fibrosis in rats via regulation of inflammatory cytokines and iNOS signaling. Animals. 2019;9:951. doi:10.3390/ani9110951

27. Caroff M, Karibian D. Structure of bacterial lipopolysaccharides. Carbohydr Res. 2003;338:2431-2447. doi:10.1016/j. carres.2003.07.010

28. Beutler B, Rietschel ET. Innate immune sensing and its roots: the story of endotoxin. Nat Rev Immunol. 2003;3:169-176. doi: $10.1038 /$ nri1004

29. Raetz CR, Whitfield C. Lipopolysaccharide endotoxins. Annu Rev Biochem. 2002;71:635-700. doi:10.1146/annurev.biochem.7 1.110601 .135414

30. Asti C, Ruggieri V, Porzio S, Chiusaroli R, Melillo G, Caselli G. Lipopolysaccharide-induced lung injury in mice. I. concomitant evaluation of inflammatory cells and haemorrhagic lung damage. Pulm Pharmacol Ther. 2000;13:61-69. doi:10.1006/pupt.2000.0231

31. Armstrong L, Medford AR, Uppington KM, et al. Expression of functional toll-like receptor-2 and-4 on alveolar epithelial cells. Am J Respir Cell Mol Biol. 2004;31:241-245. doi:10.1165/ rcmb.2004-00780C

32. McGettrick AF, O'Neill LA. Regulators of TLR4 signaling by endotoxins. Subcell Biochem. 2010;53:153-171. doi:10.1007/ 978-90-481-9078-2_7

33. Dinarello CA. Proinflammatory cytokines. Chest. 2000;118:503-508. doi:10.1378/chest.118.2.503

34. Hirohashi N, Morrison DC. Low-dose lipopolysaccharide (LPS) pretreatment of mouse macrophages modulates LPS-dependent interleukin-6 production in vitro. Infect Immun. 1996;64:1011-1015. doi:10.1128/iai.64.3.1011-1015.1996

35. Parratt JR. Nitric oxide in sepsis and endotoxaemia. J Antimicrob Chemother. 1998;41:31-39. doi:10.1093/jac/41.suppl_1.31

36. Hendrickson CM, Matthay MA. Viral pathogens and acute lung injury: investigations inspired by the SARS epidemic and the 2009 H1N1 influenza pandemic. Semin Respir Crit Care Med. 2013;34:475-486. doi:10.1055/s-0033-1351122

37. Hui DS, Azhar EI, Madani TA, et al. The continuing 2019-nCoV epidemic threat of novel coronaviruses to global health-The latest 2019 novel coronavirus outbreak in Wuhan, China. Int J Infect Dis. 2020;91:264-266. doi:10.1016/j.ijid.2020.01.009

38. Li X, Ma X. Acute respiratory failure in COVID-19: is it "typical" ARDS? Crit Care. 2020;24:198. doi:10.1186/s13054-02002911-9

39. Cai A, McClafferty B, Benson J, et al. COVID-19: catastrophic cause of acute lung injury. South Dakota Med. 2020;73:252-260.

40. Shapiro SD. The macrophage in chronic obstructive pulmonary disease. Am J Respir Crit Care Med. 1999;160:S29-S32. doi:10.1164/ajrccm.160.supplement_1.9

41. Chakraborty A, Royce SG. Use of biologics in the treatment of asthma, COPD, ACOS, and idiopathic pulmonary fibrosis. In: Dua K, Hansbro PM, Wadhwa R, Haghi M, Pont LG, Williams KA, editors. Targeting Chronic Inflammatory Lung Diseases Using Advanced Drug Delivery Systems. Academic Press; 2020:97-115. 
42. Vernooy JHJ, Dentener MA, van Suylen RJ, Buurman WA, Wouters EFM. Long-term intratracheal lipopolysaccharide exposure in mice results in chronic lung inflammation and persistent pathology. Am J Respir Cell Mol Biol. 2002;26:152-159. doi:10.1165/ ajrcmb.26.1.4652

43. George CL, Jin H, Wohlford-Lenane CL, et al. Endotoxin responsiveness and subchronic grain dust-induced airway disease. Am J Physiol Lung Cell Mol Physiol. 2001;280:L203-L13. doi:10.1152/ajplung.2001.280.2.L203

44. Kaneko Y, Takashima K, Suzuki N, Yamana K. Effects of theophylline on chronic inflammatory lung injury induced by LPS exposure in guinea pigs. Allergol Int. 2007;56:445-456. doi:10.2332/allergolint.O-07-490

45. Stolk J, Rudolphus A, Davies $P$, et al. Induction of emphysema and bronchial mucus cell hyperplasia by intratracheal instillation of lipopolysaccharide in the hamster. $J$ Pathol. 1992;167:349-356. doi:10.1002/path.1711670314

46. Vogelzang PF, van der Gulden JW, Folgering H, et al. Endotoxin exposure as a major determinant of lung function decline in pig farmers. Am J Respir Crit Care Med. 1998;157:15-18. doi:10.1164/ajrccm.157.1.9703087

47. Khedoe PPSJ, Wong MC, Wagenaar GTM, et al. The effect of PPEinduced emphysema and chronic LPS-induced pulmonary inflammation on therosclerosis development in APOE*3-LEIDEN mice. PLoS One. 2013;8:e80196-e. doi:10.1371/journal.pone.0080196

48. Taborsky J, Kunt M, Kloucek P, Lachman J, Zeleny V, Kokoska L. Identification of potential sources of thymoquinone and related compounds in Asteraceae, Cupressaceae, Lamiaceae, and Ranunculaceae families. Cent Eur J Chem. 2012;10:1899-1906. doi:10.2478/s11532-012-0114-2

49. Havlik J, Kokoska L, Vasickova S, Valterova I. Chemical composition of essential oil from the seeds of Nigella arvensis L. and assessment of its actimicrobial activity. Flavour Fragr J. 2006;21:713-717. doi:10.1002/ffj.1713

50. Goyal SN, Prajapati CP, Gore PR, et al. Therapeutic potential and pharmaceutical development of thymoquinone: a multitargeted molecule of natural origin. Front Pharmacol. 2017;8:656. doi:10.3389/fphar.2017.00656

51. Younus H. Molecular and Therapeutic Actions of Thymoquinone: Actions of Thymoquinone. 1st ed. Singapore: Springer; 2018.

52. Nemmar A, Al-Salam S, Zia S, et al. Contrasting actions of diesel exhaust particles on the pulmonary and cardiovascular systems and the effects of thymoquinone. $\mathrm{Br} J$ Pharmacol. 2011;164:1871-1882. doi:10.1111/j.1476-5381.2011.01442.x

53. Al-Gabri N, Ali A-M, Al-Attar E-S, Hamed M. Pathological study on the role of thymoquinone in experimentally induced acute lung injury in rats. Zagazig Vet J. 2017;45:228-237. doi:10.21608/ZVJZ.2017.7948

54. Al-Gabri NA, Qaid MM, El-shaer NH, Ali MH, Abudabos AM. Thymoquinone ameliorates pulmonary vascular damage induced by Escherichia coli-derived lipopolysaccharide via cytokine downregulation in rats. Environ Sci Pollut Res Int. 2019;26:18465-18469. doi:10.1007/s11356-019-05229-4

55. Pourgholamhossein F, Sharififar F, Rasooli R, et al. Thymoquinone effectively alleviates lung fibrosis induced by paraquat herbicide through down-regulation of pro-fibrotic genes and inhibition of oxidative stress. Environ Toxicol Pharmacol. 2016;45:340-355. doi:10.1016/j.etap.2016.06.019

56. Barnawi J, Tran HB, Roscioli E, et al. Pro-phagocytic effects of thymoquinone on cigarette smoke-exposed macrophages occur by modulation of the sphingosine-1-phosphate signalling system. COPD. 2016;13:653-661. doi:10.3109/15412555.2016.1153614

57. Keyhanmanesh R, Boskabady MH, Khamneh S, Doostar Y. Effect of thymoquinone on the lung pathology and cytokine levels of ovalbumin-sensitized guinea pigs. Pharmacol Rep. 2010;62:910-916. doi:10.1016/s1734-1140(10)70351-0
58. Suddek GM, Ashry NA, Gameil NM. Thymoquinone attenuates cyclophosphamide-induced pulmonary injury in rats. Inflammopharmacology. 2013;21:427-435. doi:10.1007/s10787012-0160-6

59. El Gazzar M, El Mezayen R, Marecki JC, Nicolls MR, Canastar A, Dreskin SC. Anti-inflammatory effect of thymoquinone in a mouse model of allergic lung inflammation. Int Immunopharmacol. 2006;6:1135-1142. doi:10.1016/j. intimp.2006.02.004

60. Ali MY, Akter Z, Mei Z, Zheng M, Tania M, Khan MA. Thymoquinone in autoimmune diseases: therapeutic potential and molecular mechanisms. Biomed Pharmacother. 2021;134:111157. doi:10.1016/j.biopha.2020.111157

61. El Gazzar MA, El Mezayen R, Nicolls MR, Dreskin SC. Thymoquinone attenuates proinflammatory responses in lipopolysaccharide-activated mast cells by modulating NF-kappaB nuclear transactivation. Biochim Biophys Acta. 2007;1770:556-564. doi:10.1016/j.bbagen.2007.01.002

62. Ng WK, Saiful Yazan L, Yap LH, Wan Nor Hafiza WA, How CW, Abdullah R. Thymoquinone-loaded nanostructured lipid carrier exhibited cytotoxicity towards breast cancer cell lines (MDA-MB-231 and MCF-7) and cervical cancer cell lines (HeLa and SiHa). Biomed Res Int. 2015;2015:263131. doi:10.1155/2015/263131

63. Cingi C, Eskiizmir G, Burukoğlu D, Erdoğmuş N, Ural A, Ünlü H. The histopathological effect of thymoquinone on experimentally induced rhinosinusitis in rats. Am J Rhinol Allergy. 2011;25:e268-e272. doi:10.2500/ajra.2011.25.3703

64. Kanter M. Effects of Nigella sativa seed extract on ameliorating lung tissue damage in rats after experimental pulmonary aspirations. Acta Histochem. 2009;111:393-403. doi:10.1016/j. acthis.2008.10.008

65. Erdurmus M, Yagci R, Yilmaz B, et al. Inhibitory effects of topical thymoquinone on corneal neovascularization. Cornea. 2007;26:715-719. doi:10.1097/ICO.0b013e31804f5a45

66. Sezen ŞC, Kucuk A, Özer A, et al. Assessment of the effects of levosimendan and thymoquinone on lung injury after myocardial ischemia reperfusion in rats. Drug Des Devel Ther. 2018;12:1347-1352. doi:10.2147/DDDT.S160092

67. Basavaraj S, Betageri GV. Can formulation and drug delivery reduce attrition during drug discovery and development-review of feasibility, benefits and challenges. Acta Pharmaceutica Sinica B. 2014;4:3-17. doi:10.1016/j.apsb.2013.12.003

68. Pillai K, Akhter J, Morris DL. Super aqueous solubility of albendazole in $\beta$-cyclodextrin for parenteral application in cancer therapy. J Cancer. 2017;8:913-923. doi:10.7150/jca.17301

69. Kazan A, Yesil-Celiktas O, Zhang YS. Fabrication of thymoquinone-loaded albumin nanoparticles by microfluidic particle synthesis and their effect on planarian regeneration. Macromol Biosci. 2019;19:1900182-1900187. doi:10.1002/mabi.201900182

70. Gavhane YN, Yadav AV. Loss of orally administered drugs in GI tract. Saudi Pharm J. 2012;20:331-344. doi:10.1016/j. jsps.2012.03.005

71. AbuKhader MM, Khan SA. Thymoquinone and nanoparticles: a promising approach for the clinical trials. $J$ Bionanosci. 2017;11:258-265. doi:10.1166/jbns.2017.1447

72. Ulfa SM, Sholikhah S, Utomo EP, editors. Synthesis of thymoquinone derivatives and its activity analysis: in-silico approach. Proceedings of the International Conference on Chemistry, Chemical Process and Engineering (IC3PE); Yogyakarta, Indonesia; AIP Publishing LLC; 2017. doi:10.1063/1.4978175.

73. Seigneuric R, Markey L, Nuyten DSA, et al. From nanotechnology to nanomedicine: applications to cancer research. Curr Mol Med. 2010;10:640-652. doi:10.2174/156652410792630634

74. Ventola CL. The nanomedicine revolution: part 1: emerging concepts. P T. 2012;37:512-525. 
75. Badary OA, Hamza MS, Tikamdas R. Thymoquinone: a promising natural compound with potential benefits for COVID-19 prevention and cure. Drug Des Devel Ther. 2021;15:1819-1833. doi:10.2147/DDDT.S308863

76. Rathore C, Rathbone MJ, Chellappan DK, et al. Nanocarriers: more than tour de force for thymoquinone. Expert Opin Drug Deliv. 2020;17:479-494. doi:10.1080/17425247.2020.1730808

77. Feinberg AP, Ohlsson R, Henikoff S. The epigenetic progenitor origin of human cancer. Nat Rev Genet. 2006;7:21-33. doi: $10.1038 / \operatorname{nrg} 1748$

78. Colnaghi R, Carpenter G, Volker M, O'Driscoll M. The consequences of structural genomic alterations in humans: genomic disorders, genomic instability and cancer. Semin Cell Dev Biol. 2011;22:875-885. doi:10.1016/j.semcdb.2011.07.010

79. Irigaray P, Newby JA, Clapp R, et al. Lifestyle-related factors and environmental agents causing cancer: an overview. Biomed Pharmacother. 2007;61:640-658. doi:10.1016/j.biopha.2007.10.006

80. Ding L, Getz G, Wheeler D, et al. Somatic mutations affect key pathways in lung adenocarcinoma. Nature. 2008;455:1069-1075. doi: 10.1038 /nature 07423

81. Hainaut P, Hernandez T, Robinson A, et al. IARC Database of p53 gene mutations in human tumors and cell lines: updated compilation, revised formats and new visualisation tools. Nucleic Acids Res. 1998;26:205-213. doi:10.1093/nar/26.1.205

82. Gali-Muhtasib H, Diab-Assaf M, Boltze C, et al. Thymoquinone extracted from black seed triggers apoptotic cell death in human colorectal cancer cells via a p53-dependent mechanism. Int J Oncol. 2004;25:857-866. doi:10.3892/ijo.25.4.857

83. El-Mahdy MA, Zhu Q, Wang QE, Wani G, Wani AA. Thymoquinone induces apoptosis through activation of caspase- 8 and mitochondrial events in p53-null myeloblastic leukemia HL-60 cells. Int $J$ Cancer. 2005;117:409-417. doi:10.1002/ijc.21205

84. Fahmy UA, Ahmed OA, El- Moselhy MA, Asfour HZ, Alhakamy NA. Thymoquinone loaded zein nanoparticles improves the cytotoxicity against breast cancer cells. Int J Pharmacol. 2020;16:554-561. doi:10.3923/ijp.2020.554.561

85. Ganea GM, Fakayode SO, Losso JN, van Nostrum CF, Sabliov CM, Warner IM. Delivery of phytochemical thymoquinone using molecular micelle modified poly (D, L lactide-coglycolide) (PLGA) nanoparticles. Nanotechnology. 2010;21:285104. doi:10.1088/0957-4484/21/28/285104

86. Odeh F, Ismail SI, Abu-Dahab R, Mahmoud IS, Al Bawab A. Thymoquinone in liposomes: a study of loading efficiency and biological activity towards breast cancer. Drug Deliv. 2012;19:371-377. doi:10.3109/10717544.2012.727500

87. Abu-Dahab R, Odeh F, Ismail SI, Azzam H, Al Bawab A. Preparation, characterization and antiproliferative activity of thymoquinone-beta-cyclodextrin self-assembling nanoparticles. Pharmazie. 2013;68:939-944. doi:10.1691/ph.2013.3033

88. Soni P, Kaur J, Tikoo K. Dual drug-loaded paclitaxel-thymoquinone nanoparticles for effective breast cancer therapy. J Nanopart Res. 2015;17:18. doi:10.1007/s11051-014-2821-4

89. Dehghani H, Hashemi M, Entezari M, Mohsenifar A. The comparison of anticancer activity of thymoquinone and nanothymoquinone on human breast adenocarcinoma. Iran J Pharm Res. 2015;14:539-546. doi:10.1007/s11051-014-2821-4

90. Bhattacharya S, Ahir M, Patra P, et al. PEGylated-thymoquinonenanoparticle mediated retardation of breast cancer cell migration by deregulation of cytoskeletal actin polymerization through miR-34a. Biomaterials. 2015;51:91-107. doi:10.1016/j. biomaterials.2015.01.007

91. Ahmad R, Kaus NHM, Hamid S. Synthesis and characterization of PLGA-PEG thymoquinone nanoparticles and its cytotoxicity effects in tamoxifen-resistant breast cancer cells. In: Pham PV editor. Cancer Biology and Advances in Treatment. Springer; 2018:65-82. doi:10.1007/5584_2018_302.
92. Rajput S, Puvvada N, Kumar BNP, et al. Overcoming akt induced therapeutic resistance in breast cancer through siRNA and thymoquinone encapsulated multilamellar gold niosomes. Mol Pharm. 2015;12:4214 4225. doi:10.1021/acs.molpharmaceut.5b00692

93. El-Ashmawy NE, Khedr EG, Ebeid EZM, Salem ML, Zidan AA, Mosalam EM. Enhanced anticancer effect and reduced toxicity of doxorubicin in combination with thymoquinone released from poly- $N$-acetyl glucosamine nanomatrix in mice bearing solid Ehrlish carcinoma. Eur $J$ Pharm Sci. 2017;109:525-532. doi:10.1016/j.ejps.2017.09.012

94. Ong YS, Saiful Yazan L, Ng WK, et al. Thymoquinone loaded in nanostructured lipid carrier showed enhanced anticancer activity in 4T1 tumor-bearing mice. Nanomedicine. 2018;13:1567-1582. doi: $10.2217 / \mathrm{nnm}-2017-0322$

95. Anderson B, Ho J, Brackett J, Finkelstein D, Laffel L. Parental involvement in diabetes management tasks: relationships to blood glucose monitoring adherence and metabolic control in young adolescents with insulin-dependent diabetes mellitus. $J$ Pediatr. 1997;130:257-265. doi:10.1016/s0022-3476(97)70352-4

96. Kumar A, Ilavarasan R, Jayachandran T, et al. Anti-diabetic activity of Syzygium cumini and its isolated compound against streptozotocin-induced diabetic rats. $J$ Med Plants Res. 2008;2:246-249. doi:10.5897/JMPR.9000093

97. Gothai S, Ganesan P, Park SY, Fakurazi S, Choi DK, Arulselvan P. Natural phyto-bioactive compounds for the treatment of type 2 diabetes: inflammation as a target. Nutrients. 2016;8:461. doi:10.3390/nu8080461

98. Rani R, Dahiya S, Dhingra D, Dilbaghi N, Kim KH, Kumar S. Improvement of antihyperglycemic activity of nano-thymoquinone in rat model of type- 2 diabetes. Chem Biol Interact. 2018;295:119-132. doi:10.1016/j.cbi.2018.02.006

99. Lebda MA, El-Far AH, Noreldin AE, Elewa YHA, Al Jaouni SK, Mousa SA. Protective effects of miswak (Salvadora persica) against experimentally induced gastric ulcers in rats. Oxid Med Cell Longev. 2018;2018:6703296. doi:10.1155/2018/6703296

100. Abdelwahab SI, Sheikh BY, Taha MM, et al. Thymoquinoneloaded nanostructured lipid carriers: preparation, gastroprotection, in vitro toxicity, and pharmacokinetic properties after extravascular administration. Int $J$ Nanomedicine. 2013;8:2163-2172. doi:10.2147/IJN.S44108

101. Fahmy UA, Alaofi AL, Awan ZA, Alqarni HM, Alhakamy NA. Optimization of thymoquinone-loaded coconut oil nanostructured lipid carriers for the management of ethanol-induced ulcer. AAPS PharmSciTech. 2020;21:137. doi:10.1208/s12249-020-01693-1

102. Piñeiro-Carrero VM, Piñeiro EO. Liver. Pediatrics. 2004;113:1097-1106.

103. Singh A, Ahmad I, Akhter S, et al. Nanocarrier based formulation of thymoquinone improves oral delivery: stability assessment, in vitro and in vivo studies. Colloids Surf B Biointerfaces. 2013;102:822-832. doi:10.1016/j.colsurfb.2012.08.038

104. Elmowafy M, Samy A, Raslan MA, et al. Enhancement of bioavailability and pharmacodynamic effects of thymoquinone via nanostructured lipid carrier (NLC) formulation. AAPS PharmSciTech. 2016;17:663-672. doi:10.1208/s12249-015-0391-0

105. Kalam MA, Raish M, Ahmed A, et al. Oral bioavailability enhancement and hepatoprotective effects of thymoquinone by self-nanoemulsifying drug delivery system. Mater Sci Eng C Mater Biol Appl. 2017;76:319-329. doi:10.1016/j.msec.2017.03.088

106. Mohd Sairazi NS, Sirajudeen KNS. Natural products and their bioactive compounds: neuroprotective potentials against neurodegenerative diseases. Evid Based Complement Alternat Med. 2020;2020:6565396. doi:10.1155/2020/6565396

107. Alam S, Khan ZI, Mustafa G, et al. Development and evaluation of thymoquinone-encapsulated chitosan nanoparticles for nose-tobrain targeting: a pharmacoscintigraphic study. Int J Nanomed. 2012;7:5705-5718. doi:10.2147/IJN.S35329 
108. Xiao XY, Zhu YX, Bu JY, Li GW, Zhou JH, Zhou SP. Evaluation of neuroprotective effect of thymoquinone nanoformulation in the rodent cerebral ischemia-reperfusion model. Biomed Res Int. 2016;2016:2571060. doi:10.1155/2016/2571060

109. Huang $\mathrm{L}, \mathrm{Hu} \mathrm{J}$, Huang S, et al. Nanomaterial applications for neurological diseases and central nervous system injury. Prog Neurobiol. 2017;157:29-48. doi:10.1016/j.pneurobio.2017.07.003

110. Ahmad N, Ahmad R, Alam MA, Samim M, Iqbal Z, Ahmad FJ. Quantification and evaluation of thymoquinone loaded mucoadhesive nanoemulsion for treatment of cerebral ischemia. Int J Biol Macromol. 2016;88:320-332. doi:10.1016/j.ijbioma c. 2016.03 .019

111. Ismail $\mathrm{N}$, Ismail $\mathrm{M}, \mathrm{Azmi} \mathrm{NH}$, et al. Thymoquinone-rich fraction nanoemulsion (TQRFNE) decreases $A \beta 40$ and $A \beta 42$ levels by modulating APP processing, up-regulating IDE and LRP1, and down-regulating BACE1 and RAGE in response to high fat/ cholesterol diet-induced rats. Biomed Pharmacother. 2017;95:780-788. doi:10.1016/j.biopha.2017.08.074

112. Bauer P, Laccone F, Rolfs A, et al. Trinucleotide repeat expansion in SCA17/TBP in white patients with Huntington's disease-like phenotype. J Med Genet. 2004;41:230-232. doi:10.1136/ jmg.2003.015602

113. Ramachandran S, Thangarajan S. A novel therapeutic application of solid lipid nanoparticles encapsulated thymoquinone (TQSLNs) on 3-nitroproponic acid induced Huntington's diseaselike symptoms in wistar rats. Chem Biol Interact. 2016;256:25-36. doi:10.1016/j.cbi.2016.05.020

114. Ramachandran S, Thangarajan S. Thymoquinone loaded solid lipid nanoparticles counteracts 3-Nitropropionic acid induced motor impairments and neuroinflammation in rat model of Huntington's disease. Metab Brain Dis. 2018;33:1459-1470. doi:10.1007/s11011-018-0252-0

115. Kulyar MF, Li R, Mehmood K, Waqas M, Li K, Li J. Potential influence of Nagella sativa (Black cumin) in reinforcing immune system: a hope to decelerate the COVID-19 pandemic. Phytomedicine. 2021;85:153277. doi:10.1016/j. phymed.2020.153277

116. Chakraborty A, Boer JC, Selomulya C, Plebanski M, Royce SG. Insights into endotoxin-mediated lung inflammation and future treatment strategies. Expert Rev Respir Med. 2018;12:941-955. doi:10.1080/17476348.2018.1523009
117. Chakraborty A, Royce SG, Selomulya C, Plebanski M. A novel approach for non-invasive lung imaging and targeting lung immune cells. Int $J$ Mol Sci. 2020;21:1613. doi:10.3390/ ijms21051613

118. Ammar E-SM, Gameil NM, Shawky NM, Nader MA. Comparative evaluation of anti-inflammatory properties of thymoquinone and curcumin using an asthmatic murine model. Int Immunopharmacol. 2011;11:2232-2236. doi:10.1016/j. intimp.2011.10.013

119. Paul S, Chakrabarty S, Ghosh S, et al. Targeting cellular microtubule by phytochemical apocynin exhibits autophagy-mediated apoptosis to inhibit lung carcinoma progression and tumorigenesis. Phytomedicine. 2020;67:153152. doi:10.1016/j. phymed.2019.153152

120. Chakraborty A, Royce SG, Plebanski M, Selomulya C. Glycine microparticles loaded with functionalized nanoparticles for pulmonary delivery. Int $J$ Pharm. 2019;570:118654. doi:10.1016/j. ijpharm.2019.118654

121. Darakhshan S, Bidmeshki Pour A, Hosseinzadeh Colagar A, Sisakhtnezhad S. Thymoquinone and its therapeutic potentials. Pharmacol Res. 2015;95-96:138-158. doi:10.1016/j. phrs.2015.03.011

122. Shaterzadeh-Yazdi H, Noorbakhsh M-F, Hayati F, Samarghandian S, Farkhondeh T. Immunomodulatory and anti-inflammatory effects of thymoquinone. Cardiovasc Hematol Disord Drug Targets. 2018;18:52-60. doi:10.2174/ 1871529X18666180212114816

123. Nihei T, Suzuki H, Aoki A, et al. Development of a novel nanoparticle formulation of thymoquinone with a cold wet-milling system and its pharmacokinetic analysis. Int $J$ Pharmaceut. 2016;511:455-461. doi:10.1016/j.ijpharm.2016.07.038

124. Shaarani S, Hamid S, Mohd kaus N. The Influence of pluronic F68 and F127 nanocarrier on physicochemical properties, in vitro release, and antiproliferative activity of thymoquinone drug. Pharmacognosy Res. 2017;9:12-20. doi:10.4103/09748490.199774

125. Khattabi AM, Talib WH, Alqdeimat DA. The effect of polymer length on the in vitro characteristics of a drug loaded and targeted silica nanoparticles. Saudi Pharmaceut J. 2018;26:1022-1026. doi:10.1016/j.jsps.2018.05.010
International Journal of Nanomedicine

\section{Publish your work in this journal}

The International Journal of Nanomedicine is an international, peerreviewed journal focusing on the application of nanotechnology in diagnostics, therapeutics, and drug delivery systems throughout the biomedical field. This journal is indexed on PubMed Central, MedLine, CAS, SciSearch ${ }^{\mathbb{R}}$, Current Contents ${ }^{\mathbb{B}} /$ Clinical Medicine,

\section{Dovepress}

Journal Citation Reports/Science Edition, EMBase, Scopus and the Elsevier Bibliographic databases. The manuscript management system is completely online and includes a very quick and fair peer-review system, which is all easy to use. Visit http://www.dovepress.com/ testimonials.php to read real quotes from published authors. 